\title{
Una discusión sobre la ética en los periódicos electrónicos
}

\author{
Dra. Claudia Irene de Quadros \\ Curitiba (Brasil)
}

\begin{abstract}
La irrupción de Internet en los últimos años como un nuevo medio de comunicación al que puede acceder todo el mundo está planteando numerosas cuestiones.

No se trata ya sólo de adaptarse a una nueva tecnología, sino de establecer una serie de reglas que impidan el mal uso de la red.

En el siguiente artículo, la Dra. Irene de Quadros reflexiona sobre la necesidad de plantear una Ética para los contenidos difundidos en el ciberespacio. Al mismo tiempo, la profesora brasileña advierte también del peligro de culpar a Internet de cualquier suceso que se produzca debido a su mala utilización.

su mala utilización.
En realidad, la autora de este artículo analiza los pros y los contras de la red, y apuesta por una paulatina implantación de reglas éticas, fruto de la experiencia en este terreno y en los que el
\end{abstract} periodista tenga también algo que aportar.

ética siempre se desplaza y muda, principalmente ante una revolución tecnológica. Como señala Norbert Bilbeny, profesor de la Universidad de Barcelona, los hábitos y creencias suelen cambiar de forma tan lenta que casi no percibimos las diferencias con nuestro modo de ver el mundo. Sin embargo, la percepción de los valores se acelera con cada nueva revolución tecnológica. «Y con la cultura digital el comportamiento está cambiando mucho más y a mayor velocidad.»1

La constante y vertiginosa evolución de Internet viene provocando diversos cambios en la sociedad. Bilbeny cree que vivimos en un momento de crisis ética, donde las personas están preocupadas con los posibles impactos sociales generados por el nuevo medio. La verdad es que las nuevas y desconocidas transformaciones conducen a diversos planteamientos, como: ¿Debe existir un control en Internet? «Tener que plantearnos si es buena o no la permisión total en Internet (...) es un claro indicio de que la ética responde constantemente a cambios y ella misma cambia también. $\gg^{2}$

El nuevo medio de comunicación es un mundo sin fronteras, donde conviven culturas con valores, principios morales y costumbres distintos. A veces, lo que se considera poco ético en un país es un comportamiento normal en otro. Para Nicholas Negroponte la dimensión global de la Red hará que las personas busquen un denominador

BILBENY, Norbert (1997) La revolución en la ética, Editorial Anagrama, Barcelona, p. 26.

Ibídem, p. 164.

NEGROPONTE, Nicholas (26 de julio de 1998) De la ética en la Red y la publicidad excesiva, Su Dinero, El Mundo, Madrid, p. 15 
común para la verdad, la justicia y la calidad de vida. ${ }^{3}$ Por tanto, es posible que existan en Internet costumbres compartidas y un código ético.

Mientras no se define las reglas en Internet, la polémica sobre el tema sobrepasa los límites de los grupos de discusiones del nuevo medio. Los supuestos peligros provocados por la Red también se debaten en instituciones y en otros vehículos de comunicación. La historia muestra que siempre que un medio de información ha experimentado un cambio importante se ha discutido su impacto sobre la sociedad. Lo que pasa con Internet ahora es lo mismo que enfrentó la televisión en la década de los cincuenta.

Considerando el potencial del nuevo medio, el peligro está en la pasividad de la comunidad. Es decir, no se debe aceptar los cambios como una evolución natural del determinismo técnico. Sin embargo, como señala Joseph Schmitz, atribuir a los medios de comunicación todas las transformaciones de valores y costumbres es una forma de simplificar un asunto mucho más complejo. Nuestros medios de comunicación forman parte del sistema social, por lo tanto, ellos deben inevitablemente reflejarlo. ${ }^{4}$ En otras palabras, la sociedad también impone sus deseos. «La novedad que no se adapte a nuestros intereses o motivaciones se extinguirá por sí misma o será sustituida por otra más adaptable; la que consiga hacerlo dará lugar a usos o costumbres tenidos finalmente por deseables.»"

Para establecer el orden, las comunidades procuran crear legislaciones, que prohiben algunos actos e incentivan otros. Al fin y al cabo, como recuerda Bilbeny, la ética existe precisamente para ayudar a elegir entre dos o más opciones rivales.

Los periódicos electrónicos también deben establecer códigos éticos y, así, atender los deseos de la comunidad. Durante la conferencia internacional Aspen Europe Dialogue, que tuvo lugar en Cernobbio (Italia), en mayo de 1998, los participantes estaban de acuerdo en que la sociedad exigirá una cierta postura de los medios: «(...) los periodistas debemos ser conscientes de que si no respondemos voluntariamente a los retos deontológicos que nuestro creciente poder plantea, la sociedad nos exigirá que lo hagamos por la fuerza.» ${ }^{6}$

Sin embargo, la preocupación sobre el efecto que puede provocar las posibilidades que ofrecen las nuevas tecnologías es compartida por diversos autores. El escritor García Márquez cree que el principal riesgo es que los periodistas tiendan a convertir en guetos las redacciones y se desconecten de las preocupaciones del público. «La realidad virtual, potenciada por el enorme caudal de información que fluye por los ordenadores, acabaría por sustituir la realidad de verdad en la percepción del periodista».?

Además de crear una falsa realidad, el periodista puede cometer inmoralidades durante el intento de captar la atención de un público que recibe un enorme flujo de información. Para Philip Meyer, profesor de periodismo de la Universidad de Carolina del Norte, en Estados Unidos, estas posibilidades aumentan cada día con el crecimiento de la confusión ética provocada por la era de la información. Por eso, Meyer cree que es

4 SCHMITZ, Joseph (1997) Structural Relations, Electronic Media, and Social Change: The Public Electronic Network and the Homeless, Virtual Culture. Identity \& Communication in Cybersociety. Sage Publications, London, p. 84

BILBENY, Norbert (1997) La revolución en la ética, Editorial Anagrama, Barcelona, p. 37.

6 MONTOYA, Roberto(10 de mayo de 1998) Hay que estimular el pluralismo mediante leves antimonopolio. Debate de los directores de Le Monde, The Economist y El Mundo, moderado por Umberto Eco; El Mundo, Madrid, p. 34.

7 GOR, Francisco(10 de noviembre de 1996) La importancia de ser lector, El País, Madrid, p. 16. 
fundamental establecer el orden: «Pienso que el hombre no es capaz de juzgarse a sî mismo. Entonces, es una buena estrategia dejar el juicio de nuestros actos en manos de otros para lograr ser honestos. A los periodistas los enjuicia el público, que es el que genera el mercado, también otros periodistas, que ejercen una presión social; lo hacen nuestros propios colegas y empleadores.» ${ }^{8}$

\section{¿Internet es un medio tan peligroso como se divulga?}

Hoy, con el avance técnico, se plantean diversos problemas relativos a ética. En el periodismo electrónico, una de las principales preocupaciones es con relación al riesgo de que los diarios en la Red pierdan la credibilidad por culpa de sitios que suelen publicar mensajes injuriosos y delectivos con el afán de llamar la atención del usuario. Por eso, no se puede descartar la posibilidad de que la sociedad clasifique Internet, de manera general, como un medio peligroso para las costumbres y los valores deseables.

Otros acontecimientos, como el suicidio colectivo de los miembros de una secta llamada erróneamente cibernética, han servido para presentar la Red como una amenaza a la sociedad. El caso de la secta Heaven's Gate (La puerta del cielo), de la que 39 integrantes se quitaron la vida a finales de marzo de 1997 en una mansión cercana a San Diego, Estados Unidos, ha generado una cantidad abrumadora de informaciones en muy poco tiempo. Es que la secta ha dejado un vídeo explicando sus planes, además de una página web con datos sobre su ideología. Después que la prensa tradicional ha publicado el suicidio colectivo, mucha gente quiso conectarse a este sitio en Internet para saber más detalles sobre los integrantes de la secta que se mataron para subir a un platillo volante que venía tras el cometa Hale-Bopp, según la versión presentada por la prensa. El exceso de interesados acabó por atascar la conexión de esta página web. Pero, el hecho de que una secta posea un sitio en la Red no significa que sea cibernética. El Vaticano mantiene diversas direcciones en Internet y no por esto el catolicismo puede calificarse ahora de una religión cibernética.

El diario El Mundo (30 de marzo de 1997) tituló así uno de los reportajes sobre el suicidio de los seguidores de Heaven's Gate: «Una "cibersecta" comandada por un líder castrado». El hecho de que la palabra cibersecta estuviera entre comillas podría justificar el cuidado del editor en no levantar falsas alarmas con relación a Internet. Pero, el lead del material («La mayoría de los 18 suicidas varones de la secta de cibernautas...») apunta la típica prensa amarilla. Por lo tanto, la preocupación del editor era solamente lingüística. Las comillas se utilizaron para señalar un neologismo.

El País (30 de marzo de 1997) relató diversas versiones sobre el origen de la secta, asegurando que tuvo varios nombres a lo largo de los años. De acuerdo con este diario, Heaven's Gate recibió gran atención informativa durante dos decenios. Desde 1994, la secta intentaba buscar nuevos seguidores en la Red enviando anuncios masivos por correo electrónico. Por eso, El País publicó en el mismo artículo la preocupación de que una secta suicida estuviera divulgando su ideología en Internet: «La página en Internet de La Puerta del Cielo (...) será sin duda utilizada como «prueba» de que Internet es perjudicial,

8 GRONEMEYER, María Elena (1996) No hay un periodismo incorruptible, Cuadernos de Información, número 11, Universidad Católica de Chile, p. 24 
pero los expertos advierten de que esa deducción es injusta. Como declaró Karen Coyle de la organización Usuarios de Ordenadores por la Responsabilidad Social, no se puede culpar a Internet, igual que no se puede culpar al cometa.» ${ }^{9}$

Sin duda, algunas noticias sobre determinadas páginas web (publicadas en la prensa tradicional) pueden atemorizar a los lectores que no tienen acceso a la Red. Sin posibilidad de evaluar las ventajas y desventajas de Internet, estos lectores tienden a creer que el nuevo medio es realmente peligroso para el orden público.

Algunos titulares, como: «Dos cibernautas se suicidan siguiendo una receta de la Red» (El Mundo, 13 de marzo de 1997), «Internet permite adquirir fármacos prohibidos o más caros en España»(El País, 16 de mayo de 1997), «Los guerrilleros de América Latina asaltan Internet» (El Mundo, 10 de agosto de 1997) o «Una secta ofrece por Internet hijos mediante la clonación de un padre»(El País, 10 de junio de 1997), también muestran la preocupación de los medios informativos con relación a la falta de control en la red de redes. Es evidente que la prensa no debe dejar de tratar estos temas, pero tiene la obligación de evitar alarmas sociales ante un medio que todavía desconoce una gran parte de la población y está en fase de desarrollo. Al revés, como señala Juan Luis Cebrián, se puede poner en riesgo la libertad de expresión. «Si en el caos informal de las infocarreteras no se establecen códigos de circulación que los hagan cumplir, la desorientación del usuario puede llegar al paroxismo. Pero se procede de esa forma, muchos verán levantarse de nuevo el fantasma de la censura, y una abdicación en la defensa de la libertad absoluta de los cibernautas.» ${ }^{10}$

Existen diversos grupos que intentan controlar de alguna manera los contenidos de Internet. La primera movilización tuvo lugar en Estados Unidos, en 1990, para protestar contra los mensajes pornográficos difundidos en la Red. Hoy, el internauta puede adquirir diversos programas, como SurfWatch (Vigilancia del Surfeo) o Netnanny (la Niñera de la Red), que impiden el acceso a páginas web donde aparecen palabras como sexo o pornografía. Sin embargo, es importante señalar: «(...) en Internet es práticamente imposible encontrarse contenidos explícitamente sexuales por mera casualidad.» ${ }^{11}$

El 6 de diciembre de 1995 pasó a la historia de Internet, cuando el Congreso de Estados Unidos promulgó la Ley de Decencia de las Comunicaciones (Communication Decency Act, CDA). Esta ley limita la difusión de contenidos pornográficos en la Red y establece la posibilidad de imponer multas de hasta 100.000 dólares o condenas de cárcel de hasta dos años. Pero, el intento de controlar algunos de los contenidos de Internet ha generado polémica entre los usuarios de la red de redes, que acusaron a los parlamentarios americanos de cercenar el derecho de expresarse libremente.

Sin embargo, en la Red no existen fronteras. Eso significa que los mismos contenidos prohibidos en Estados Unidos pueden transferirse a un servidor de otro país, donde la CDA no está en vigor. Es decir, los internautas norteamericanos, se asi lo desean, acceden fácilmente a los contenidos que son vetados en su país.

9 Cavestany, Juan (30 de marzo de 1997) La locura de la Puerta del Cielo, El País, Madrid, p. 6.

10 CEBRIÁN, Juan Luis (1998) La Red, Taurus, Madrid, p. 70.

11 DE LAS FUENTES, Alberto (1 de junio de 1997) Viaje al lado oscuro de Internet, Su Dinero, El Mundo, Madrid, p. 10. 
Aunque Internet tenga establecido protocolos técnicos para intercambiar información en todo el mundo, todavía no existe una legislación internacional para controlar actos delictivos de algunos sitios.

La Unión Europea se ha comprometido a intentar una acción contra la pornografía en Internet. Mientras no sean creadas leyes específicas para la Red, diversos grupos vienen luchando contra los crímenes cometidos en el ciberespacio. Por ejemplo, la asociación belga Morkhoven contra la pedofilia es conocida por denunciar pederastas que difunden la pornografía infantil por medio de la red de redes.

También existen grupos que combaten el racismo, como Perdona pero no Olvides $O$ Artistas contra el Racismo. Si en algún momento ellos encuentran algo en una publicación en Internet que puede considerarse delito, inmediatamente informan a las autoridades locales

Sin embargo, el poder de la policía en estos casos (racismo o pornografía infantil) es limitado. En el ciberespacio, como quedó dicho anteriormente, no existen legislaciones específicas y de alcance internacional.

Mientras no se define una legislación para Internet, la tecnología punta también se está utilizando para intentar bloquear las acciones de los hackers, capaces de incluir imágenes, borrar archivos completos o manejar el contenido de un sitio como si fuera el propio proveedor. Pero, aún así ninguna dirección en la Red está libre de un ataque terrorista virtual. El 12 de septiembre de 1998, piratas informáticos que acceden ilegalmente a ordenadores conectados a Internet invadieron el sistema del diario electrónico estadounidense The New York Times. Las noticias de la home page fueron sustituidas por mujeres desnudas y los editores tuvieron que suspender de forma temporal el acceso a diversas secciones afectadas. Los hackers justificaron el ataque como una protesta por la cobertura del diario en el caso Kevin Mitnick, preso desde 1995 por robar informaciones secretas de diversas empresas a través de la Red.

El ataque de los hackers al diario The New York Times (archivado en la dirección http://www.antionline.com/archives/pages/www.nytimes.com) fue el primero a un gran vehículo de comunicación. Sin embargo, los expertos en seguridad de Internet creen que eso puede pasar con otros periódicos digitales ${ }^{12}$, hecho que asusta a los empresarios del nuevo medio. Al fin y al cabo, los hackers pueden perjudicar los negocios electrónicos de un diario, sobre todo porque llegan a controlar su audiencia. Para no afectar la imagen de medio, la primera estrategia de los editores y programadores del The New York Times fue impedir el acceso de los usuarios durante el día (domingo) que más recibe visitas.

Los piratas informáticos, si logran entrar en el servidor de un diario digital, también pueden censurar una noticia y acabar por transgredir el principal código de ética creado por los primeros hackers*, el derecho a la libre información. Esa posibilidad no se

12 ARMAÑANZAS, Emy; Javier Díaz Noci y Koldo Meso (1996) Información y ervicios multimedia en la

era del ciberespacio, Editorial Ariel, Barcelona, p. 163. El origen del nombre está relacionado con un grupo de alumnos del MIT (Instituto Tecnológico de Massachusetts), que, sala de las terminales de ordenadores de la institución por la noche y sin autorización. Estos hackers contribuyeron a la historia de la informática porque desarrollaro nuevos progan es un derecho de todos. A finales de los 80 y principios de los 90 la prensa enpezó a unizar el térnino hackers como piratas informáticos que acceden ilegatron archivos completos o manejar el contenido de un sitio como si fuera el propio proveedor. 
descartó en el caso del ataque virtual a la versión electrónica del periódico The New York Times. Por lo menos es lo que se puede concluir de la declaración del presidente de la The New York Times Electronic Media Company, Martin Nisenholtz, publicada el 13 de septiembre de 1998 por el diario estadounidense** Él especuló que el ataque del grupo de hackers HFG coincidió con el incremento del tráfico del sitio y la continuación de la publicación del informe del fiscal independiente Kenneth W. Starr sobre el caso Whitewater. En este caso, el presidente de Estados Unidos Bill Clinton es acusado de cometer irregularidades en un negocio de bienes raíces cuando ejercía el cargo de gobernador de Arkansas, en la década de 1980. Pero, a principios de 1998 también se incluyó en esta investigación la acusación de acoso sexual a una becaria de la Casa Blanca, hecho que despertó gran interés de los medios de comunicación de todo el mundo y, evidentemente, del público.

Ante tantas transformaciones del nuevo medio, el papel del periodista es crucial. No solamente por la información que él distribuye, sino también por la estructura ética que debe construir en Internet. Durante el debate sobre el futuro del periodismo digital, realizado a principios de junio de 1997 por la Universidad de Columbia, en Nueva York, el presidente del The New York Times Arthur Ochs Sulzberger Junior, señalaba que el periodista va a enfrentar muchos desafíos, porque el contenido no sólo es información, son las personas y los nuevos medios los que cambian la ecuación. Sin embargo, el periodista debe procurar saber qué es lo que debe hacer. ${ }^{1.3}$

El problema es que Internet y sus aspectos éticos todavía están en fase de desarro1lo. El periodista intenta buscar el rumbo cierto del periodismo digital, adaptando la información a un nuevo medio. Pero, los avances vertiginosos de la tecnología crean un ambiente que también es desconocido para este profesional. La experiencia llega poco a poco, después de cometer algunos errores. La cobertura en la Red de algunos casos, como el juicio del ex jugador de fútbol americano O.J. Simpson (acusado de encargar matar a su ex mujer y al novio de ésta), han confirmado el poder de difusión de Internet y de los usuarios.

Dos días después de publicar la polémica portada donde O.J. Simpson aparece con una mirada culpable y una cara siniestra debido a los efectos de la fotografía, Jim Gaines, editor jefe de la revista Time, decidió adelantar la columna del próximo número de la publicación en Internet. Como el asunto se estaba debatiendo en los medios de comunicación de todo el país, Gaines pensó que era necesario dar explicaciones a los lectores de la revista de forma inmediata. A través de un mensaje divulgado por la AOL (America Online), responsable de la versión electrónica de Time, el consejo editorial pedía disculpas por haber ofendido a alguien y manifestaba que no había intenciones racistas en la publicación de la fotografía de O.J. Simpson. Este hecho, que tuvo lugar el 22 de junio

** «(..) Martin Nisenholtz, president of the division, said late Sunday that the company did not yet know how the hacker organization, HFG — or Hacking for Girlies — had breached its security. But he speculated that the attack was timed to coincide with the increased traffic to the site in the wake of the publication of the report by the Whitewater independent counsel, Kenneth W. Starr.(...)»

13 September 13,1998. Times's Web Site Hacked, The New York Times, www.nytimes.com. 
de 1994, pasó a la historia de Internet. Fue la primera vez que los internautas pudieron discutir un asunto con un periodista por medio de correo electrónico. El editor Jim Gaines recibió muchos mensajes de protesta contra la portada de la revista y contestó a cada una(o) de ellas(os) personalmente, probando así que Internet también es un medio para discutir la ética. 